(2) Open Access Full Text Article

\title{
Increased programmed death ligand-I expression predicts poor prognosis in hepatocellular carcinoma patients
}

This article was published in the following Dove Press journal:

OncoTargets and Therapy

2 August 2016

Number of times this article has been viewed

\author{
Xiaobin $\mathrm{Gu}^{\prime}$ \\ Xian-Shu Gao' \\ Wei Xiong ${ }^{2}$ \\ Wei Guo ${ }^{3}$ \\ Linjun $\mathrm{Han}^{3}$ \\ Yun Bai' \\ Chuan Peng' \\ Ming Cui' \\ Mu Xie' \\ 'Department of Radiation Oncology, \\ Peking University First Hospital, \\ Peking University, Beijing, People's \\ Republic of China; 'Department of \\ Oncology, Tangshan People's Hospital, \\ Hebei, People's Republic of China; \\ ${ }^{3}$ Graduate School of Medicine, Hebei \\ North University, Zhangjiakou, Hebei, \\ People's Republic of China
}

Purpose: Accumulating studies have investigated the prognostic and clinical significance of programmed death ligand-1 (PD-L1) expression in patients with hepatocellular carcinoma (HCC); however, the results were conflicting and inconclusive. We conducted a meta-analysis to combine controversial data to precisely evaluate this issue.

Methods: Relevant studies were thoroughly searched on PubMed, Web of Science, and Embase until April 2016. Eligible studies were evaluated by selection criteria. Hazard ratio (HR) with 95\% confidence interval (CI) was used to estimate the prognostic role of PD-L1 for overall survival (OS) and disease-free survival (DFS)/recurrence-free survival (RFS). Odds ratio (OR) with $95 \%$ CI were selected to assess the relationship between PD-L1 and clinicopathological features of HCC patients. Publication bias was tested using Begg's funnel plot.

Results: A total of seven studies published from 2009 to 2016 were included for meta-analysis. The data showed that high PD-L1 expression was correlated to shorter OS (HR $=2.09$, 95\% CI: $1.66-2.64, P<0.001)$ as well as poor DFS/RFS (HR $=2.3,95 \% \mathrm{CI}: 1.46-3.62, P<0.001)$. In addition, increased PD-L1 expression was also associated with tumor differentiation ( $\mathrm{HR}=1.51,95 \% \mathrm{CI}: 1-2.29, P=0.05)$, vascular invasion $(\mathrm{HR}=2.16,95 \% \mathrm{CI}: 1.43-3.27$, $P<0.001$ ), and $\alpha$-fetoprotein (AFP; HR $=1.46,95 \% \mathrm{CI}$ : $1-2.14, P=0.05$ ), but had no association with tumor stage, tumor size, hepatitis history, sex, age, or tumor multiplicity. No publication bias was found for all analyses.

Conclusion: This meta-analysis revealed that overexpression of PD-L1 was predictive for shortened OS and DFS/RFS in HCC. Furthermore, increased PD-L1 expression was associated with less differentiation, vascular invasion, and AFP elevation.

Keywords: programmed death ligand-1, hepatocellular carcinoma, prognosis, meta-analysis

\section{Introduction}

Hepatocellular carcinoma (HCC) is the main form of liver malignancy as well as the fifth most prevalent neoplasm and the third most common cause of cancer death worldwide. ${ }^{1,2}$ In developing countries, HCC represents a much heavier health care burden, especially for males. ${ }^{1}$ Hepatitis B or C virus (HBV or HCV) infection is a major cause of $\mathrm{HCC}$; in addition, $\mathrm{HBV} / \mathrm{HCV}$-infected cohorts have a significantly increased risk of $\mathrm{HCC}$ incidence compared with $\mathrm{HBV} / \mathrm{HCV}$-negative cohorts. ${ }^{3,4}$ Growing evidence indicates that the chronic inflammation caused by virus infection plays an important role in HCC development. ${ }^{5}$ Persistent expression of various cytokines in the process of chronic inflammation and recruitment of immune cells to tumor milieu confer an immunosuppressive microenvironment in the liver, which in turn promotes tumorigenesis and metastasis. ${ }^{6-8}$
Correspondence: Xian-Shu Gao Department of Radiation Oncology, Peking University First Hospital,

Peking University, Beijing, People's Republic of China

Tel +86 I0 83575239

Fax +86 106655 I788

Email doctorgaoxs@126.com 
Recent attention had been attracted by a series of molecules named "immune inhibitory checkpoints," such as programmed death 1 (PD-1) and programmed death ligand-1 (PD-L1). ${ }^{9}$ PD-L1, also known as B7 homologue 1 (B7-H1), is one of the ligands of PD-1. PD-1 belongs to B7-CD28 superfamily and is mainly expressed on the surface of T-, B-, and NK cells, ${ }^{10}$ whereas PD-L1 is known to be expressed on different malignant tumor cells and a variety of other conventional immune cells. ${ }^{11}$ The combination and interaction between PD-1 and PD-L1 deliver negative costimulatory signals and thus protect tumor cells from immune attacks. ${ }^{12}$ Overexpression of PD-L1 has been reported to be linked with worse prognosis in various cancer types, including non-small-cell lung cancer, ${ }^{13}$ renal cell carcinoma, ${ }^{14}$ gastric carcinoma, ${ }^{15}$ brain tumors, ${ }^{16}$ and breast cancer. ${ }^{17}$ Different research groups have investigated the prognostic role of PD-L1 expression in HCC; ${ }^{18-24}$ however, the results were inconclusive. Some studies ${ }^{18-20}$ showed that upregulated PD-L1 expression predicted poor survival in HCC, whereas other reports ${ }^{22,24}$ presented negative results. Therefore, there is a need to combine the conflicting data to have an explicit clarification. In this study, we employed a meta-analysis and collected results from eligible studies to explore prognostic value of PD-L1 expression for HCC patients; furthermore, the relationship between PD-L1 expression and clinicopathological features in HCC was also evaluated.

\section{Materials and methods PRISMA guidelines}

This meta-analysis was performed in accordance with PRISMA (Preferred Reporting Items for Systematic Reviews and Meta-Analyses) guidelines, ${ }^{25}$ and the PRISMA checklist is presented in Table $\mathrm{S} 1$.

\section{Literature search}

The electronic databases of Embase, Web of Science, and PubMed were comprehensively searched (up to April 2016). The search terms were: "hepatocellular carcinoma" (MeSH terms), "hepatocellular cancer," "HCC," "liver cancer," "programmed cell death-ligand 1," "PD-L1," "B7 homolog 1," "B7-H1," "cluster of differentiation 274," and "CD274." References from retrieved articles were also screened for potential studies.

\section{Study selection}

To be included studies had to meet the following criteria: 1) HCC was histopathologically diagnosed; 2) the expression of PD-L1 was determined by immunohistochemistry
(IHC) or other methods; 3) data concerning the relationships between PD-L1 and survival including overall survival (OS) and disease-free survival (DFS)/recurrence-free survival (RFS) and/or clinical features in HCC was reported or could be computed according to Tierney's method;26 4) patients were stratified in two categories classified as PD-L1 positive (high) or PD-L1 negative (low); 5) published as full-text articles; and 6) published in English. The following articles were excluded: 1) meeting abstracts, reviews, case reports, or letters; 2) nonhuman studies; and 3) absence of necessary data for hazard ratio (HR) and 95\% confidence interval (CI) or odds ratio (OD) and 95\% CI estimation.

\section{Data extraction}

Two investigators (XB Gu and XS Gao) independently extracted the following information from included studies: first author's name, year of publication, country, histological type, tumor stage, differentiation, treatment methods, sample size, detection approach for PD-L1, and HRs and 95\% CIs for OS, DFS, and RFS, if provided. Discrepancies between the two reviewers were settled by discussion.

\section{Statistical analysis}

HR with 95\% CI was utilized to evaluate the association between elevated PD-L1 expression and OS, DFS, and RFS. If the data were not directly provided in text, then they were calculated from the survival curves by Tierney's method. ${ }^{26}$ OR with 95\% CI were calculated to assess the effects of PD-L1 expression on clinicopathological features. Heterogeneity was examined by using Q and $I^{2}$ test. If $I^{2}>50 \%$ or $P_{\mathrm{h}}<0.1$, which indicated significant heterogeneity, a randomeffects model was used; otherwise, a fixed-effects model was adopted. Potential risk of publication bias was estimated using Begg's funnel plot. All analyses were performed using Stata version12.0 (Stata Corporation, College Station, TX, USA). $P$-value $<0.05$ indicates statistically significant.

\section{Results}

\section{Characteristics of included publications}

Through initial database searching, 198 records were identified. After removing duplicates, 134 records were screened for eligibility by title/abstract reading; then, 121 articles were discarded because they were carried out in animals, were irrelevant, or were not published in English (one was in Chinese and one was in Polish), or a combination of them. Subsequently, 13 records were left for eligibility evaluation. Thereafter, six records were excluded due to insufficient data for HR and 95\% CI and OR and 95\% CI calculation. 


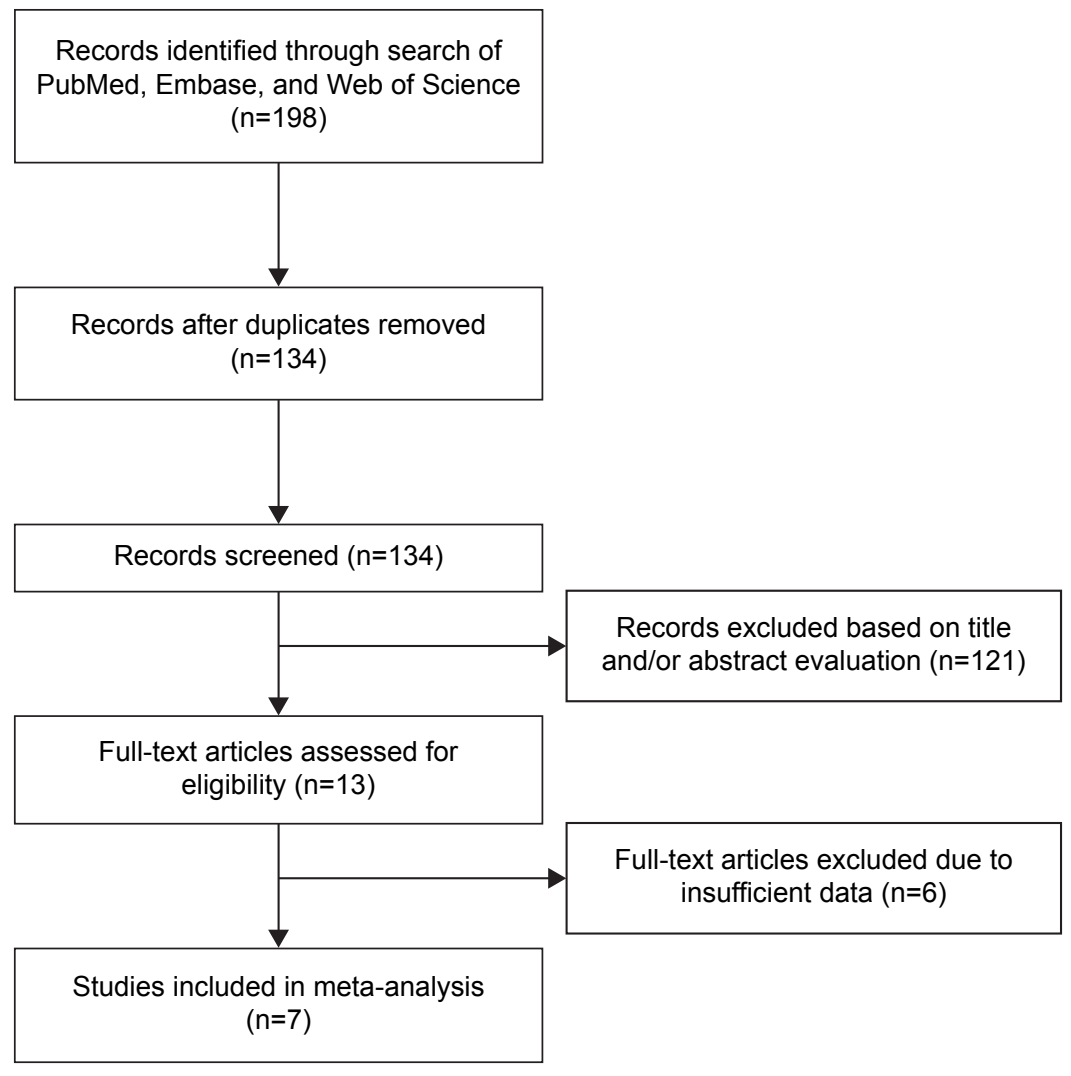

Figure I Flow diagram showing literature filtration process.

Finally, seven studies ${ }^{18-24}$ published from 2009 to 2016 were included in this meta-analysis. The literature confirmation process is shown in Figure 1. The total sample size of seven studies was 901 , ranging from 58 to 240 . Five studies ${ }^{18-22}$ were conducted in Asian countries and two studies ${ }^{23,24}$ were performed in Western countries. The detailed information of the included studies is depicted in Table 1.

\section{Prognostic role of PD-LI expression for OS and DFS/RFS}

All of the seven studies ${ }^{18-24}$ (comprising 901 patients) investigated the association between PD-L1 expression and OS in HCC. The pooled HR was 2.09 , with $95 \%$ CI: $1.66-2.64$, $P<0.001$; in addition, there was no heterogeneity $\left(I^{2}=0\right.$, $P_{\mathrm{h}}=0.701$; Figure 2). For DFS/RFS, there were four studies with 487 patients that explored the correlation. The combined HR and $95 \%$ CI were: $\mathrm{HR}=2.3,95 \% \mathrm{CI}: 1.46-3.62, P<0.001$, although with heterogeneity $\left(R=56.4 \%, P_{\mathrm{h}}=0.076\right.$; Figure 2$)$.

\section{Association between PD-LI expression and clinicalpathological factors}

ORs and 95\% CIs were calculated to evaluate the association between PD-L1 expression and clinicopathological factors, including age, sex, tumor stage, tumor differentiation, tumor size, vascular invasion, hepatitis history, $\alpha$-fetoprotein (AFP), and tumor multiplicity. At least three studies were included for analysis of each parameter. As listed in Table 2, the results demonstrated that PD-L1 overexpression was correlated with poor tumor differentiation ( $\mathrm{HR}=1.51,95 \% \mathrm{CI}: 1-2.29, P=0.05$; $\left.P^{2}=31.7 \%, P_{\mathrm{h}}=0.222\right)$, vascular invasion ( $\mathrm{HR}=2.16,95 \%$ CI: $\left.1.43-3.27, P<0.001 ; P=42.3 \%, P_{\mathrm{h}}=0.158\right)$, and AFP $(\mathrm{HR}=1.46$, $95 \%$ CI: $\left.1-2.14, P=0.05 ; P^{2}=0, P_{\mathrm{h}}=0.527\right)$. However, there was no association between PD-L1 expression and tumor stage, tumor size, hepatitis history, sex, age, or tumor multiplicity.

\section{Publication bias}

Begg's funnel plot was utilized to test potential publication bias. The results showed that there was no publication bias for OS or DFS/RFS analysis (Begg's test: $P=0.368$ for OS and $P=0.734$ for DFS/RFS; Figure 3). Moreover, there was no publication bias for the analysis of clinicopathological features (Table 2).

\section{Discussion}

A number of studies have investigated the clinical significance of PD-L1 expression in patients with HCC, but the 


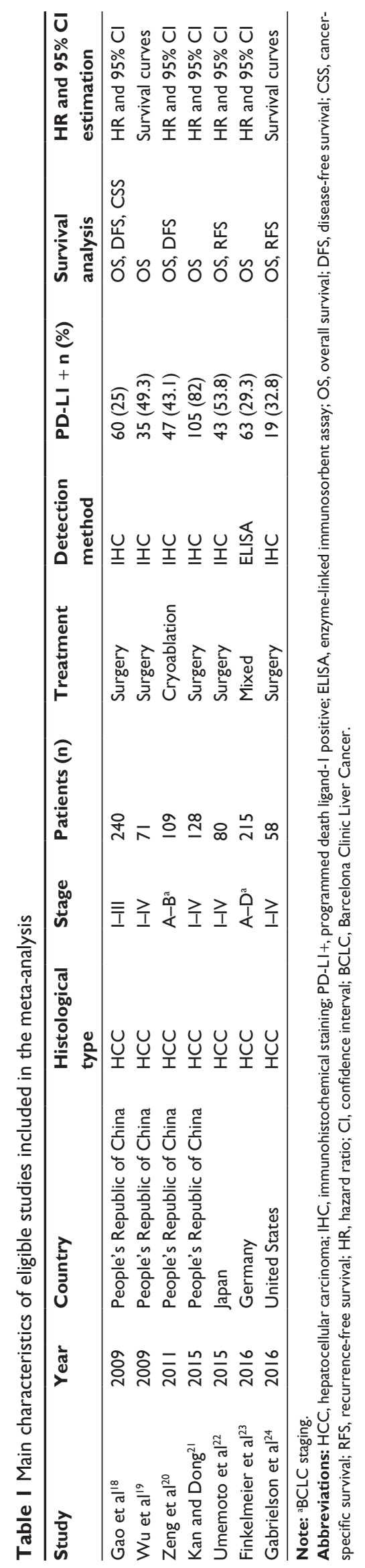

results were inconclusive. In this study, we collected data from seven eligible studies and assessed the prognostic and clinical value of PD-L1 for HCC. Our results showed that high PD-L1 expression predicted poor OS and DFS/RFS in HCC; in addition, high PD-L1 expression was associated with tumor differentiation, vascular invasion, and AFP. The results suggested that PD-L1 expression had diagnostic value for poor differentiation and neovascularization; meanwhile, it provided implications for shortened survival to stratify risk patients. To our knowledge, this was the first meta-analysis exploring both the prognostic and clinical value of PD-L1 expression for HCC patients as an individual study.

PD-1 and its two ligands PD-L1 and PD-L2 could combine to limit the activity of peripheral T-cells in chronic inflammation and autoimmunity. ${ }^{10,27-29}$ The PD-1/PD-1 ligand system is an intrinsic mechanism in physiological conditions that maintains balance between proinflammatory and anti-inflammatory activity and protects our bodies from harmful adverse effects caused by immune responses. Unfortunately, this system is aberrantly activated in cancer patients and promotes tolerance to tumor antigens, resulting in immune suppression in the tumor microenvironment. ${ }^{30}$ At the same time, PD-1/PD-1 ligand system is also a promising target to activate antitumor immunity. Monoclonal antibodies targeting PD-1 and PD-L1 have showed encouraging effects and prolonged the stabilization of disease for a variety of cancer types, including melanoma, non-small-cell lung cancer, renal cell carcinoma, colorectal cancer, and gastric cancer. ${ }^{31,32}$ In addition, PD-L1 expression was also explored as a prognostic biomarker for different cancers including HCC. PD-1 and PD-L1 interaction could render immune suppression in multiple ways such as suppressing $\mathrm{T}$-cell activation, inducing $\mathrm{CD} 8^{+}$cell apoptosis, and recruiting immunosuppressive cells. ${ }^{33}$

Previous studies have investigated the prognostic value of PD-L1 in various solid tumors including non-small-cell lung cancer,,$^{13}$ gastric carcinoma, ${ }^{15}$ and breast cancer. ${ }^{17}$ Our results showed that elevated PD-L1 expression was correlated with poor survival, which was in accordance with the findings in other cancers. ${ }^{13,14,34,35}$ Furthermore, we also investigated the clinical significance of PD-L1 expression, through which we found that PD-L1 was correlated with poor differentiation, vascular invasion, and AFP. The cancer immunoediting theory suggested that an immunosuppressive environment had already existed during the initiation of tumor occurrence; ${ }^{30}$ therefore, PD-L1 was likely to be expressed in poorly differentiated HCC. Additionally, evidence showed that VEGF overexpression could promote accumulation of immunosuppressive cells, which may further 
A Study ID

ES $(95 \% \mathrm{Cl})$

Weight (\%)

Gao et $\mathrm{al}^{18}$

Wu et al ${ }^{19}$

Zeng et $\mathrm{al}^{20}$

Kan and Dong ${ }^{21}$

Umemoto et $\mathrm{al}^{22}$

Finkelmeier et $\mathrm{al}^{23}$

Gabrielson et al24

Overall $\left(P^{2}=0.0 \%, P=0.701\right)$

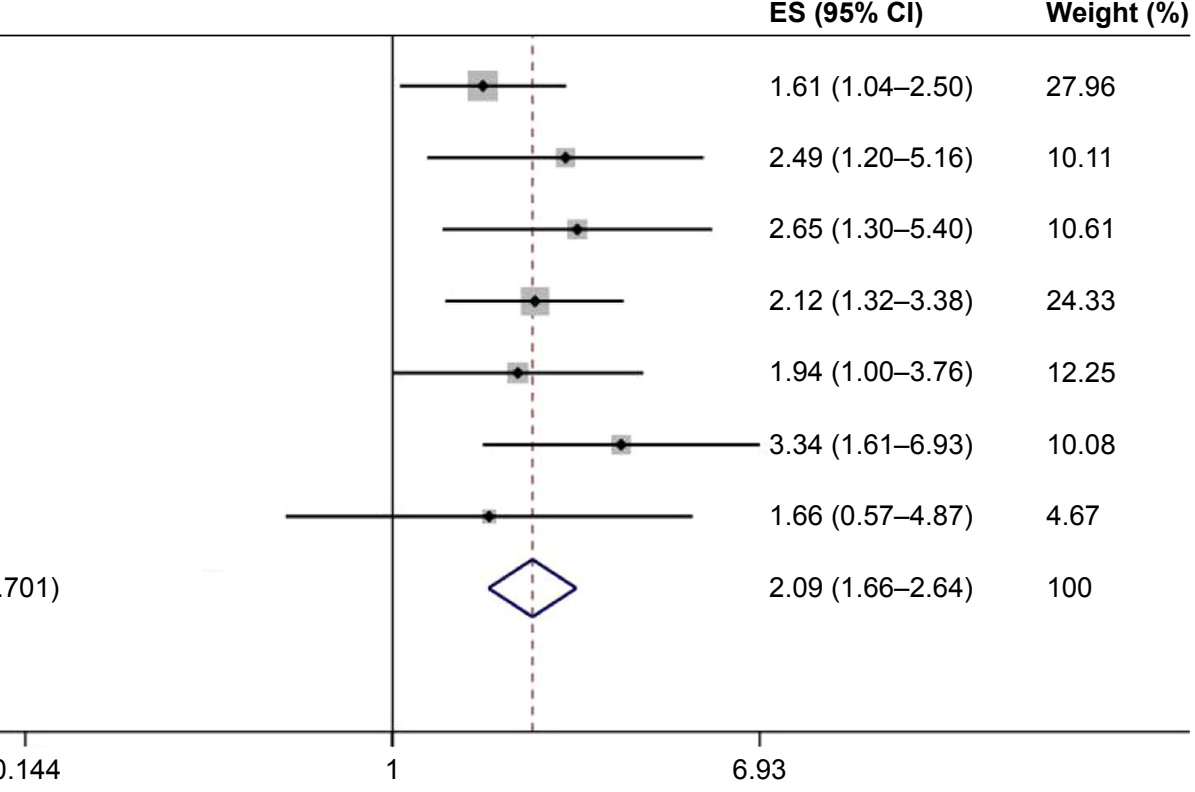

B study ID

ES (95\% CI)

Weight (\%)

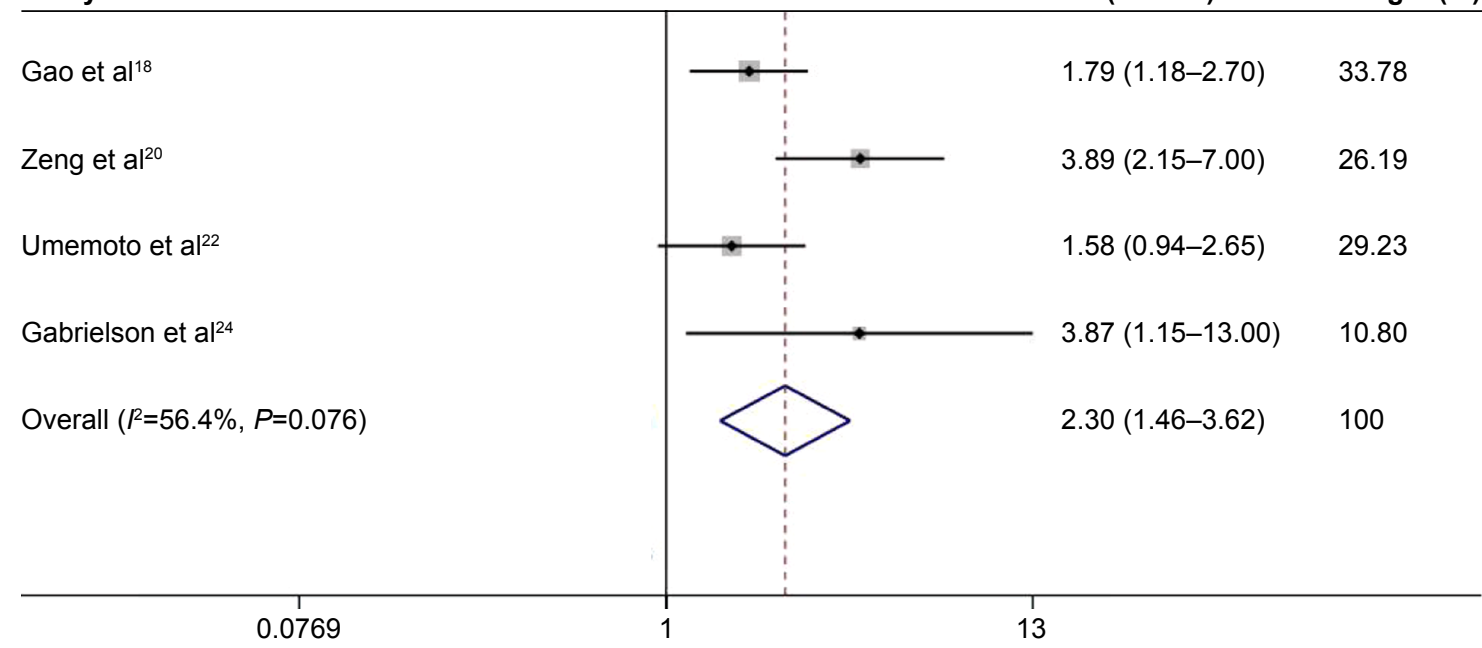

Figure 2 Forrest plot of HRs for the association of PD-LI expression with (A) OS and (B) DFS/RFS in HCC patients.

Note: Weights are from random effects analysis.

Abbreviations: HRs, hazard ratios; OS, overall survival; PD-LI, programmed death ligand-I; DFS, disease-free survival; RFS, recurrence-free survival; HCC, hepatocellular carcinoma; $\mathrm{Cl}$, confidence interval; $\mathrm{ES}$, effect size.

Table 2 Association between PD-LI expression and clinical features of HCC patients in meta-analysis

\begin{tabular}{|c|c|c|c|c|c|c|c|c|}
\hline \multirow[t]{2}{*}{ Factors } & \multirow{2}{*}{$\begin{array}{l}\text { Studies } \\
\text { (n) }\end{array}$} & \multirow{2}{*}{$\begin{array}{l}\text { Patients } \\
\text { (n) }\end{array}$} & \multirow{2}{*}{$\begin{array}{l}\text { Analytical } \\
\text { model }\end{array}$} & \multirow[t]{2}{*}{ OR $(95 \% \mathrm{Cl})$} & \multirow[t]{2}{*}{$P$-value } & \multicolumn{2}{|c|}{ Heterogeneity } & \multirow{2}{*}{$\begin{array}{l}\text { Publication } \\
\text { bias Begg's P }\end{array}$} \\
\hline & & & & & & $I^{2}(\%)$ & $P_{h}$ & \\
\hline Tumor stage (III-IV vs I-II) & 5 & 615 & REM & $1.13(0.47-2.74)$ & 0.784 & 73.5 & 0.005 & 0.806 \\
\hline $\begin{array}{l}\text { Tumor differentiation (poor vs } \\
\text { moderate/high) }\end{array}$ & 4 & 506 & FEM & $1.51(I-2.29)$ & 0.05 & 31.7 & 0.222 & 0.734 \\
\hline Vascular invasion (yes vs no) & 4 & 487 & FEM & $2.16(1.43-3.27)$ & $<0.001$ & 42.3 & 0.158 & 0.497 \\
\hline Tumor size $(>5 \mathrm{~cm}$ vs $<5 \mathrm{~cm})$ & 4 & 557 & REM & $1.66(0.6-4.57)$ & 0.329 & 82.9 & 0.001 & 0.734 \\
\hline Hepatitis history (yes vs no) & 4 & 557 & REM & $1.8(0.8-4.08)$ & 0.158 & 61.5 & 0.05 & I \\
\hline $\operatorname{AFP}(>20 \mathrm{ng} / \mathrm{mL}$ vs $<20 \mathrm{ng} / \mathrm{mL})$ & 4 & 557 & FEM & $1.46(I-2.14)$ & 0.05 & 0 & 0.527 & i \\
\hline Sex (male vs female) & 4 & 557 & FEM & $0.95(0.59-1.53)$ & 0.833 & 0 & 0.534 & I \\
\hline Age $(>$ median vs $<$ median $)$ & 3 & 477 & FEM & $0.82(0.55-1.22)$ & 0.329 & 0 & 0.876 & I \\
\hline Tumor multiplicity (multiplicity vs single) & 3 & 429 & FEM & $1.23(0.8-1.89)$ & 0.338 & 0 & 0.715 & I \\
\hline
\end{tabular}

Notes: $P$-values were obtained by using the 'metan' programm in STATA V.12.0. $P$-value $<0.05$ was considered as statistically significant.

Abbreviations: PD-LI, programmed death ligand-I; FEM, fixed-effects model; REM, random-effects model; AFP, $\alpha$-fetoprotein; HCC, hepatocellular carcinoma; OR, odds ratio; $\mathrm{Cl}$, confidence interval. 

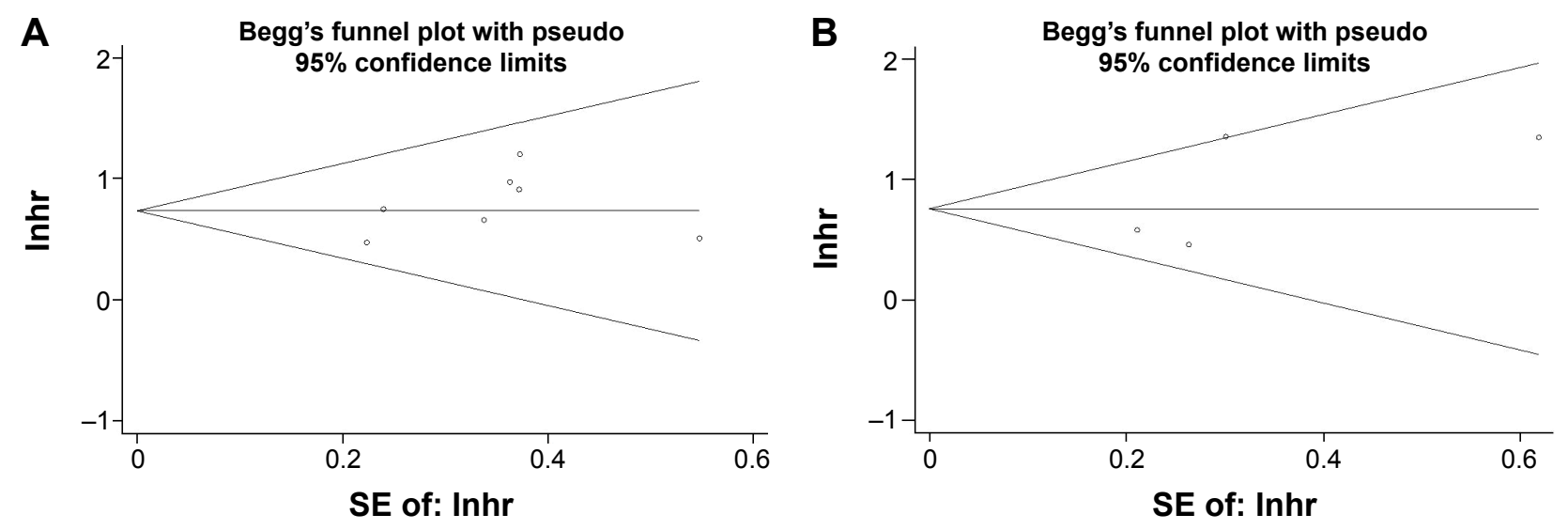

Figure 3 Begg's funnel plot for publication bias tests in (A) OS and (B) DFS/RFS in HCC.

Abbreviations: OS, overall survival; DFS, disease-free survival; RFS, recurrence-free survival; HCC, hepatocellular carcinoma; SE, standard error; Inhr, natural logarithm of hazard ratio.

induce PD-L1 expression. ${ }^{36}$ We have noticed that a few studies $^{37-39}$ had investigated the prognostic role of PD-L1 in HCC using meta-analysis. However, these studies only enrolled HCC as a small part of their studies, along with other solid tumors. Each study only included two studies of HCC for analysis. Compared with these studies, our metaanalysis containing seven studies published up to 2016 was more comprehensive and timely. Therefore, our results are more reliable and persuasive.

Several limitations need to be pointed out. First, heterogeneity still existed for DFS/RFS analysis, which may be caused by different patient selection standards and different antibodies for IHC use. Second, in our meta-analysis, only articles published in English were included. In the literature selection process of this meta-analysis, two studies published in languages other than English were excluded, but one of them was an animal study and the other was an irrelevant study. So, these two studies would have been eliminated for other reasons besides language. Therefore, inclusion of English papers did not substantially introduce potential publication bias, as suggested by Begg's test (all $P$-value $>0.05$ for publication bias tests). Third, six studies used IHC to detect PD-L1 expression, while one study selected the enzyme-linked immunosorbent assay method, which may cause slight heterogeneity. Therefore, further studies using uniform criteria are needed.

\section{Conclusion}

This meta-analysis revealed that high expression of PD-L1 was predictive for poor OS and DFS/RFS in HCC patients. Furthermore, high PD-L1 expression was associated with poor tumor differentiation, vascular invasion, and AFP elevation. Our results suggest that PD-L1 is an effective prognosis biomarker for HCC. However, because of limitations of this study, well-designed investigations using uniform criteria are warranted to verify our results.

\section{Acknowledgment}

This work was supported by a grant from the Clinical Features Research of Capital (number Z141107002514160).

\section{Disclosure}

The authors report no conflicts of interest in this work.

\section{References}

1. Torre LA, Bray F, Siegel RL, Ferlay J, Lortet-Tieulent J, Jemal A. Global cancer statistics, 2012. CA Cancer J Clin. 2015;65(2):87-108.

2. Forner A, Llovet JM, Bruix J. Hepatocellular carcinoma. Lancet. 2012;379(9822):1245-1255.

3. El-Serag HB. Epidemiology of viral hepatitis and hepatocellular carcinoma. Gastroenterology. 2012;142(6):1264-1273.

4. Goodgame B, Shaheen NJ, Galanko J, El-Serag HB. The risk of end stage liver disease and hepatocellular carcinoma among persons infected with hepatitis C virus: publication bias? Am J Gastroenterol. 2003;98(11):2535-2542.

5. Makarova-Rusher OV, Medina-Echeverz J, Duffy AG, Greten TF. The yin and yang of evasion and immune activation in HCC. J Hepatol. 2015;62(6):1420-1429.

6. Huang A, Zhang B, Yan W, et al. Myeloid-derived suppressor cells regulate immune response in patients with chronic hepatitis $\mathrm{B}$ virus infection through PD-1-induced IL-10. J Immunol. 2014;193(11):5461-5469.

7. $\mathrm{Xu} \mathrm{D}, \mathrm{Fu}$ J, Jin $\mathrm{L}$, et al. Circulating and liver resident CD4+CD25+ regulatory $\mathrm{T}$ cells actively influence the antiviral immune response and disease progression in patients with hepatitis B. J Immunol. 2006;177(1):739-747.

8. Matsuzaki K, Murata M, Yoshida K, et al. Chronic inflammation associated with hepatitis $\mathrm{C}$ virus infection perturbs hepatic transforming growth factor beta signaling, promoting cirrhosis and hepatocellular carcinoma. Hepatology. 2007;46(1):48-57.

9. Kassel R, Cruise MW, Iezzoni JC, Taylor NA, Pruett TL, Hahn YS. Chronically inflamed livers up-regulate expression of inhibitory B7 family members. Hepatology. 2009;50(5):1625-1637.

10. Keir ME, Butte MJ, Freeman GJ, Sharpel AH. PD-1 and its ligands in tolerance and immunity. Ann Rev Immunol. 2008;26:677-704.

11. Afreen S, Dermime S. The immunoinhibitory B7-H1 molecule as a potential target in cancer: killing many birds with one stone. Hematol Oncol Stem Cell Ther. 2014;7(1):1-17. 
12. Iwai Y, Ishida M, Tanaka Y, Okazaki T, Honjo T, Minato N. Involvement of PD-L1 on tumor cells in the escape from host immune system and tumor immunotherapy by PD-L1 blockade. Proc Natl Acad Sci U S A. 2002;99(19):12293-12297.

13. Aguiar PN Jr, Santoro IL, Tadokoro H, et al. The role of PD-L1 expression as a predictive biomarker in advanced non-small-cell lung cancer: a network meta-analysis. Immunotherapy. 2016;8(4):479-488.

14. Iacovelli R, Nole F, Verri E, et al. Prognostic role of PD-L1 expression in renal cell carcinoma. A systematic review and meta-analysis. Target Oncol. 2016;11(2):143-148.

15. Wu C, Zhu Y, Jiang J, Zhao J, Zhang XG, Xu N. Immunohistochemical localization of programmed death-1 ligand-1 (PD-L1) in gastric carcinoma and its clinical significance. Acta Histochem. 2006; 108(1):19-24.

16. Jacobs JF, Idema AJ, Bol KF, et al. Regulatory T cells and the PD-L1/ PD-1 pathway mediate immune suppression in malignant human brain tumors. Neurooncology. 2009;11(4):394-402.

17. Ghebeh H, Mohammed S, Al-Omair A, et al. The B7-H1 (PD-L1) $\mathrm{T}$ lymphocyte-inhibitory molecule is expressed in breast cancer patients with infiltrating ductal carcinoma: correlation with important high-risk prognostic factors. Neoplasia. 2006;8(3):190-198.

18. Gao Q, Wang XY, Qiu SJ, et al. Overexpression of PD-L1 significantly associates with tumor aggressiveness and postoperative recurrence in human hepatocellular carcinoma. Clin Cancer Res. 2009;15(3) 971-979.

19. Wu K, Kryczek I, Chen L, Zou W, Welling TH. Kupffer cell suppression of CD8+ T cells in human hepatocellular carcinoma is mediated by B7-H1/programmed death-1 interactions. Cancer Res. 2009;69(20):8067-8075.

20. Zeng Z, Shi F, Zhou L, et al. Upregulation of circulating PD-L1/PD-1 is associated with poor post-cryoablation prognosis in patients with HBV-related hepatocellular carcinoma. PloS One. 2011;6(9):e23621.

21. Kan G, Dong W. The expression of PD-L1 APE1 and P53 in hepatocellular carcinoma and its relationship to clinical pathology. Eur Rev Med Pharmacol Sci. 2015;19(16):3063-3071.

22. Umemoto Y, Okano S, Matsumoto Y, et al. Prognostic impact of programmed cell death 1 ligand 1 expression in human leukocyte antigen class I-positive hepatocellular carcinoma after curative hepatectomy. J Gastroenterol. 2015;50(1):65-75.

23. Finkelmeier F, Canli O, Tal A, et al. High levels of the soluble programmed death-ligand (sPD-L1) identify hepatocellular carcinoma patients with a poor prognosis. Eur J Cancer. 2016;59:152-159.

24. Gabrielson A, Wu Y, Wang H, et al. Intratumoral CD3 and CD8 T-cell densities associated with relapse free survival in HCC. Cancer Immunol Res. 2016;4(5):419-430.
25. Moher D, Liberati A, Tetzlaff J, Altman DG. Preferred reporting items for systematic reviews and meta-analyses: the PRISMA statement. PLoS Med. 2009;6(7):e1000097.

26. Tierney JF, Stewart LA, Ghersi D, Burdett S, Sydes MR. Practical methods for incorporating summary time-to-event data into meta-analysis. Trials. 2007;8:16.

27. Barber DL, Wherry EJ, Masopust D, et al. Restoring function in exhausted CD8 T cells during chronic viral infection. Nature. 2006;439(7077):682-687.

28. Latchman Y, Wood CR, Chernova T, et al. PD-L2 is a second ligand for PD-1 and inhibits T cell activation. Nat Immunol. 2001;2(3): 261-268.

29. Topalian SL, Drake CG, Pardoll DM. Targeting the PD-1/B7-H1 (PD-L1) pathway to activate anti-tumor immunity. Curr Opin Immunol. 2012;24(2):207-212.

30. Schreiber RD, Old LJ, Smyth MJ. Cancer immunoediting: integrating immunity's roles in cancer suppression and promotion. Science. 2011; 331(6024):1565-1570.

31. Brahmer JR, Tykodi SS, Chow LQM, et al. Safety and activity of anti-PD-L1 antibody in patients with advanced cancer. $N$ Engl J Med. 2012;366(26):2455-2465.

32. Topalian SL, Hodi FS, Brahmer JR, et al. Safety, activity, and immune correlates of anti-PD-1 antibody in cancer. $N$ Eng. J Med. 2012; 366(26):2443-2454.

33. Pauken KE, Wherry EJ. Overcoming T cell exhaustion in infection and cancer. Trends Immunol. 2015;36(4):265-276.

34. Xu F, Feng G, Zhao H, et al. Clinicopathologic significance and prognostic value of $\mathrm{B} 7$ homolog 1 in gastric cancer: a systematic review and meta-analysis. Medicine. 2015;94(43):e1911.

35. Huang B, Chen L, Bao C, et al. The expression status and prognostic significance of programmed cell death 1 ligand 1 in gastrointestinal tract cancer: a systematic review and meta-analysis. Onco Targets Ther. 2015;8:2617-2625.

36. Terme M, Pernot S, Marcheteau E, et al. VEGFA-VEGFR pathway blockade inhibits tumor-induced regulatory $\mathrm{T}$-cell proliferation in colorectal cancer. Cancer Res. 2013;73(2):539-549.

37. Lin Z, Xu Y, Zhang Y, et al. The prevalence and clinicopathological features of programmed death-ligand 1 (PD-L1) expression: a pooled analysis of literatures. Oncotarget. 2016;79(12):15033-15046.

38. Wu P, Wu D, Li L, Chai Y, Huang J. PD-L1 and survival in solid tumors: a meta-analysis. PloS One. 2015;10(6):e0131403.

39. Jin Y, Zhao J, Shi X, Yu X. Prognostic value of programed death ligand 1 in patients with solid tumors: a meta-analysis. J Cancer Res Therap. 2015;11(Suppl 1):C38-C43. 


\section{Supplementary material}

Table SI PRISMA checklist

\begin{tabular}{|c|c|c|c|}
\hline Section/topic & Number & Checklist item & $\begin{array}{l}\text { Reported on } \\
\text { page number }\end{array}$ \\
\hline
\end{tabular}

Title

Title

Abstract

Structured summary

2

\section{Introduction}

Rationale

Objectives

Methods

Protocol and registration

Eligibility criteria

Information sources

Search

Study selection

Data collection process

Data items

Risk of bias in individual studies

Summary measures

Synthesis of results

Risk of bias across studies

Additional analyses

\section{Results}

Study selection

Study characteristics

Risk of bias within studies

Results of individual

studies

Synthesis of results

Risk of bias across studies
Identify the report as a systematic review, meta-analysis, or both.

Provide a structured summary including, as applicable: background; objectives; data sources; study eligibility criteria, participants, and interventions; study appraisal and synthesis methods; results; limitations; conclusions and implications of key findings; systematic review registration number.

Describe the rationale for the review in the context of what is already known. Provide an explicit statement of questions being addressed with reference to participants, interventions, comparisons, outcomes, and study design (PICOS).

Indicate if a review protocol exists, if and where it can be accessed (eg, Web address), 5 and, if available, provide registration information including registration number.

Specify study characteristics (eg, PICOS, length of follow-up) and report

\section{5}

characteristics (eg, years considered, language, publication status) used as criteria for eligibility, giving rationale.

Describe all information sources (eg, databases with dates of coverage, contact with study authors to identify additional studies) in the search and date last searched.

Present full electronic search strategy for at least one database, including any limits used, such that it could be repeated.

State the process for selecting studies (ie, screening, eligibility, included in systematic review, and, if applicable, included in the meta-analysis).

Describe method of data extraction from reports (eg, piloted forms, independently, in duplicate) and any processes for obtaining and confirming data from investigators. List and define all variables for which data were sought (eg, PICOS, funding sources) and any assumptions and simplifications made.

Describe methods used for assessing risk of bias of individual studies (including specification of whether this was done at the study or outcome level), and how this information is to be used in any data synthesis.

State the principal summary measures (eg, risk ratio, difference in mean values).

Describe the methods of handling data and combining results of studies, if done, including measures of consistency (eg, $l^{2}$ ) for each meta-analysis.

Specify any assessment of risk of bias that may affect the cumulative evidence (eg, publication bias, selective reporting within studies).

Describe methods of additional analyses (eg, sensitivity or subgroup analyses, metaregression), if done, indicating which were pre-specified.

Give numbers of studies screened, assessed for eligibility, and included in the review, with reasons for exclusions at each stage, ideally with a flow diagram.

For each study, present characteristics for which data were extracted (eg, study size, PICOS, follow-up period) and provide the citations.

Present data on risk of bias of each study and, if available, any outcome level assessment (see item I2).

For all outcomes considered (benefits or harms), present, for each study: (a) simple summary data for each intervention group, (b) effect estimates and confidence intervals, ideally with a forest plot.

Present results of each meta-analysis done, including confidence intervals and measures of consistency.

Present results of any assessment of risk of bias across studies (see Item 15). regression [see Item 16]). 
Table SI (Continued)

\begin{tabular}{|c|c|c|c|}
\hline Section/topic & Number & Checklist item & $\begin{array}{l}\text { Reported on } \\
\text { page number }\end{array}$ \\
\hline \multicolumn{4}{|l|}{ Discussion } \\
\hline Summary of evidence & 24 & $\begin{array}{l}\text { Summarize the main findings including the strength of evidence for each main } \\
\text { outcome; consider their relevance to key groups (eg, health care providers, users, } \\
\text { and policy makers). }\end{array}$ & 9,10 \\
\hline Limitations & 25 & $\begin{array}{l}\text { Discuss limitations at study and outcome level (eg, risk of bias), and at review-level } \\
\text { (eg, incomplete retrieval of identified research, reporting bias). }\end{array}$ & II \\
\hline Conclusions & 26 & $\begin{array}{l}\text { Provide a general interpretation of the results in the context of other evidence, and } \\
\text { implications for future research. }\end{array}$ & II \\
\hline \multicolumn{4}{|c|}{ P } \\
\hline Funding & 27 & $\begin{array}{l}\text { Describe sources of funding for the systematic review and other support (eg, supply } \\
\text { of data); role of funders for the systematic review. }\end{array}$ & 12 \\
\hline
\end{tabular}

Notes: Reproduced from Moher D, Liberati A, Tetzlaff J, Altman DG. Preferred reporting items for systematic reviews and meta-analyses: the PRISMA statement. PLoS Medicine. 2009;6(7): Epub July 2009.' For more information, visit: www.prisma-statement.org.

Abbreviations: PRISMA, Preferred Reporting Items for Systematic Reviews and Meta-Analyses; PICOS, Participants, Intervention, Control, Outcome, Study design.

\section{Reference}

1. Moher D, Liberati A, Tetzlaff J, Altman DG. Preferred reporting items for systematic reviews and meta-analyses: the PRISMA statement. PLoS Med. 2009;6(7):Epub July 2009.

\section{Publish your work in this journal}

OncoTargets and Therapy is an international, peer-reviewed, open access journal focusing on the pathological basis of all cancers, potential targets for therapy and treatment protocols employed to improve the management of cancer patients. The journal also focuses on the impact of management programs and new therapeutic agents and protocols on

\section{Dovepress}

patient perspectives such as quality of life, adherence and satisfaction. The manuscript management system is completely online and includes a very quick and fair peer-review system, which is all easy to use. Visit http://www.dovepress.com/testimonials.php to read real quotes from published authors.

Submit your manuscript here: http://www.dovepress.com/oncotargets-and-therapy-journal 